\title{
Formulation, Optimization, and in vitro Characterization of Curcumin Loaded Liposomes for Colonic Delivery
}

\author{
Ankita Tiwari, Sanjay K Jain* \\ Pharmaceutics Research Projects Laboratory, Department of Pharmaceutical Sciences, Dr. Harisingh Gour Vishwavidyalaya, Sagar, Madhya Pradesh, INDIA.
}

\begin{abstract}
Background: Curcumin has been extensively employed in the treatment of several diseases in traditional medicine, including cancer. The main obstacles that avert its approval as a therapeutic moiety are its low aqueous solubility and low in vivo bioavailability. Liposomes have been recognized as effective carrier systems owing to their ability to solubilize hydrophobic molecules and to change their pharmacokinetic attributes. This study was intended at developing Eudragit S 100 coated alginate beads bearing curcumin loaded liposomes for colonic delivery. Methods: The liposomes were prepared by the film casting method. The optimization of various formulation and process variables was done by Box-Behnken design using DesignExpert $\circledast$ Software.Three variables i.e.HSPC:Chol molar ratio $\left(X_{1}\right)$,curcumin concentration $\left(X_{2}\right)$, and sonication time $\left(X_{3}\right)$ were selected as independent variables and entrapment efficiency of curcumin, polydispersity index, and vesicle size were selected as dependent variables. Results: The optimized liposomes had an average particle size of $109.8 \pm 1.4 \mathrm{~nm}$, polydispersity index $0.218 \pm 1.2$, zeta potential $+19.30 \pm 2.46 \mathrm{mV}$, and with entrapment
\end{abstract}

efficiency $70.16 \pm 1.6 \%$. These liposomes were entrapped in eudragit coated beads and these beads were characterized for their size, swelling index and in vitro drug release. The in vitro drug release depicted that no release was observed till $6 \mathrm{hrs}$ and a sustained and significant drug release was noted after $6.5 \mathrm{hr}$. Conclusion: The stability studies indicated that liposomes were stable at $4^{\circ} \mathrm{C}$ depicting little aggregation of the vesicles. The research suggested that curcumin-loaded liposomes bearing eudragit coated calcium alginate beads can be effectively used for colonic delivery. Key words: Curcumin, Colon, Liposomes, Alginate beads, Optimization.

\section{Correspondence}

Dr. Sanjay K. Jain,

Professor of Pharmaceutics, Department of Pharmaceutical Sciences, Dr. Harisingh Gour Vishwavidyalaya, Sagar-470 003, Madhya Pradesh, INDIA.

Email id: drskjainin@yahoo.com

DOI: 10.5530/ijpi.2021.4.73

\section{INTRODUCTION}

Colorectal cancer (CRC) ranks second in cancer-associated mortality rates across the globe. Research depicted that dysregulation of a few cellular signaling pathways leads to the genesis of malignant phenotypes. ${ }^{1}$ Turmeric (Curcuma longa) has been medicinally employed due to the presence of a yellow-colored pigment known as curcumin. Curcumin (i.e. diferuloylmethane) possesses many pharmacological properties, like antioxidant, anti-inflammatory, antitumor, anti-bacterial, wound healing, antispasmodic, anticoagulant, and hepatoprotective properties. ${ }^{2}$ It has been reported that curcumin has potent cytotoxicity against many cancer cell lines encompassing, breast, colon, leukemia, ovarian, and prostate. ${ }^{3,4}$ From the in vitro investigations of curcumin, it has been disclosed that it interacts with many molecular targets like growth factors, cytokines, etc. influencing tumor growth and angiogenesis. Despite its remarkable pharmacological activities and non-toxicity, curcumin manifests poor bioavailability and fast metabolism that restrict its activity. Experiments have portrayed its poor absorption from the intestine after oral delivery in rats due to its metabolism into dihydro- and tetrahydro-curcumin. Effective administration of chemotherapeutic drugs especially to tumors and approaches to enhance their bioavailability have been an important challenge in the arena of research. Amidst numerous carrier systems, liposomes have found wide applications owing to their capability to change the pharmacokinetics of the encapsulated drugs by slow clearance and longer circulation time. ${ }^{5}$ Liposomes are ideal drug delivery systems for curcumin due to the high lipophilicity of the drug. This research work discusses a novel liposomal preparation of curcumin, its optimization using Design of Experiment (DoE) and in vitro characterizations. These liposomes were further entrapped in eudragit coated beads for making them suitable for colon specific drug delivery.

\section{MATERIALS}

Curcumin was obtained as a gift sample from Sanat Products Limited (New Delhi). Hydrogenated soy phosphatidylcholine (HSPC) was obtained as a gift sample from Lipoid, Germany, Cholesterol $(\mathrm{CH})$ was obtained from Sigma (New Delhi, India). Methanol and chloroform were purchased from (Merck Life Science Pvt. Ltd., Mumbai; India), Ultrapure water (Millipore, Bedford, MA) was used throughout the experiment. All other chemicals were of the highest grade.

\section{METHODS}

\section{Preparation of liposomes}

Liposomes were prepared by thin-film hydration method as described by Bangham et al. ${ }^{6}$ HSPC, cholesterol, and curcumin were dissolved in chloroform: methanol mixture $(4: 1)$ in a round-bottomed flask. The solvent was evaporated at $40{ }^{\circ} \mathrm{C}$ using a rotary evaporator (Buchi type, York Sci Co., Bombay) under reduced pressure to form a thin film. The flask was kept under a vacuum in a desiccator. It was hydrated using phosphate buffer saline $(\mathrm{pH} 7.4)$ at $65^{\circ} \mathrm{C}$ for $1 \mathrm{hr}$. The suspension containing multilamellar vesicles was left for 5-6 hrs to permit swelling of the vesicles. It was sonicated using a probe sonicator for $3 \mathrm{~min}$ at $4 \pm 1^{\circ} \mathrm{C}$. The liposomal suspension was passed through Sephadex G-50 columns 
to eliminate traces of the unentrapped drug. It was then lyophilized and stored at $4^{\circ} \mathrm{C}$.

\section{Optimization of Liposomes}

The various variables employed for the preparation of liposomes were optimized using systematic DoE optimization principle. With the help of Design-Expert ${ }^{\oplus}$ software (10.0, Stat-Ease Inc., Minneapolis, USA) and 3-factors, 3-levels Box-Behnken design (BBD) was utilized to estimate the 3-D response surfaces by scrutinizing the effect of independent variables i.e. Molar ratio of HSPC: Chol $\left(\mathrm{X}_{1}\right)$, curcumin concentration $\left(\mathrm{X}_{2}\right)$, and sonication time $\left(\mathrm{X}_{3}\right)$ on selected dependent variables i.e., percentage entrapment efficiency CUR $\left(\mathrm{Y}_{1}\right)$ and polydispersity index (PDI) $\left(\mathrm{Y}_{2}\right)$, and vesicle size $\left(\mathrm{Y}_{3}\right)$. All independent variables are depicted as $+1,0$, and -1 , which represents high, medium, and low levels, respectively. In the design matrix, 17 runs were formed on Three- level, Three-factors (Table 1). Several model parameters i.e. multiple correlation coefficient $\left(\mathrm{R}^{2}\right)$, adjusted multiple correlation coefficient/(adjusted $\mathrm{R}^{2}$ ), predicted multiple correlation coefficient (predicted $\mathrm{R}^{2}$ ), coefficient of variation $(\mathrm{CV})$, and predicted residual sum of the square were compared to analyze the model. The response surface analysis (RSA) was executed by $3 \mathrm{D}$ response surfaces by Design- Expert ${ }^{\oplus}$ software (10.0, Stat-Ease Inc., Minneapolis, USA)

\section{Characterization of curcumin loaded liposomes}

The prepared formulations were characterized for various attributes viz. surface morphology, vesicle size, zeta potential, PDI and in vitro drug release.

\section{Surface morphology}

The morphology of the prepared liposomes was assessed by transmission electron microscopy (JEM-200 CX; JEOL, Tokyo, Japan). The liposomal sample was placed on a grid using the drop-casting method. It was air-dried and observed under transmission electron microscope.

\section{Size, zeta potential, and Polydispersity index}

Vesicle size (z-average), size distribution (polydispersity index), and zeta potential of curcumin- loaded liposomes were determined by NanoPlus-3 (Version 5.01, Micromeritics Instrument Corporation, Particulate Systems, Norcross, GA, USA) by Photon Correlation Spectroscopy (PCS). A diluted sample was taken in the cuvette and vesicle size was determined. The zeta potential of the prepared liposomes was determined by Helmholtz-Smoluchowski equation from their electrophoretic mobility at field strength $20 \mathrm{~V} / \mathrm{cm}$.

\section{Entrapment efficiency}

The entrapment efficiency of the liposomes was estimated by removing the unentrapped drug with the aid of Sephadex G-50 minicolumn (i.e. centrifugation technique). ${ }^{7,8}$ Sephadex G-50 (1.0 g) was swollen in $0.9 \% \mathrm{NaCl}$ at $25^{\circ} \mathrm{C}$ with occasional shaking for $4-5 \mathrm{hrs}$. It led to the formation of the gel. It was stored at $4^{\circ} \mathrm{C}$ and filled in minicolumn. Liposomes were added to this prepared Sephadex minicolumn and centrifuged at $2000 \mathrm{rpm}$ for $3 \mathrm{~min}$ to remove the unentrapped drug. These liposomes were lysed by $0.1 \%$ Triton X-100 and were filtered through a 0.22 -micron membrane filter $(25 \mathrm{~mm}$, Chromatopak). The filtrate was analyzed for drug content by HPLC method using Column SPHER-100 $\mathrm{C}_{18} 100 \mathrm{~A}(250 \mathrm{~mm} \times 4.6 \mathrm{~mm}, 5 \mu \mathrm{m}$ particle size $)$ with a mobile phase of acetic acid : water (50:50) having a flow rate of $1.2 \mathrm{ml} /$ min, injection volume of $10 \mathrm{ml}$ and detection wavelength at $422 \mathrm{~nm}$ [Shimadzu Prominence HPLC (Shimadzu Corporation, Kyoto, Japan)].

$$
\text { Encapsulation efficiency }(\%)=\frac{\begin{array}{l}
\text { Total curcumin }(\mathrm{mg})- \\
\text { Free curcumin }(\mathrm{mg})
\end{array}}{\text { Total curcumin }(\mathrm{mg})} \times 100
$$

\begin{tabular}{|c|c|c|c|c|c|c|}
\hline \multirow[b]{2}{*}{ Runs } & \multirow{2}{*}{$\begin{array}{c}\text { Factor } 1 \\
\text { Molar ratio } \\
\text { HSPC:Chol }\end{array}$} & \multirow{2}{*}{$\begin{array}{c}\text { Factor } 2 \\
\begin{array}{c}\text { Curcumin } \\
\text { concentration } \\
(\mathrm{mM})\end{array}\end{array}$} & \multirow{2}{*}{$\begin{array}{c}\text { Factor } 3 \\
\begin{array}{c}\text { Sonication time } \\
\text { (min) }\end{array}\end{array}$} & \multicolumn{3}{|c|}{ Responses } \\
\hline & & & & $\begin{array}{l}\% \text { EE } \\
\text { CUR }\end{array}$ & PDI & Vesicle size $(\mathrm{nm})$ \\
\hline 1 & -1.00 & 0.00 & -1.00 & 59.82 & 0.218 & 114.6 \\
\hline 2 & 1.00 & 1.00 & 0.00 & 71.26 & 0.167 & 113.8 \\
\hline 3 & -1.00 & 0.00 & 1.00 & 51.25 & 0.111 & 106.5 \\
\hline 4 & -1.00 & 1.00 & 0.00 & 58.82 & 0.188 & 109.0 \\
\hline 5 & 0.00 & 0.00 & 0.00 & 70.57 & 0.093 & 109.6 \\
\hline 6 & 1.00 & -1.00 & 0.00 & 72.30 & 0.091 & 111.0 \\
\hline 7 & 0.00 & 0.00 & 0.00 & 70.17 & 0.070 & 110.8 \\
\hline 8 & 0.00 & 0.00 & 0.00 & 69.75 & 0.081 & 110.2 \\
\hline 9 & 0.00 & 0.00 & 0.00 & 70.10 & 0.079 & 110.3 \\
\hline 10 & 0.00 & -1.00 & -1.00 & 69.36 & 0.161 & 117.4 \\
\hline 11 & 0.00 & -1.00 & 1.00 & 63.91 & 0.091 & 110.0 \\
\hline 12 & 0.00 & 1.00 & -1.00 & 71.77 & 0.247 & 119.0 \\
\hline 13 & 1.00 & 0.00 & -1.00 & 72.77 & 0.169 & 118.0 \\
\hline 14 & -1.00 & -1.00 & 0.00 & 55.42 & 0.120 & 110.9 \\
\hline 15 & 1.00 & 0.00 & 1.00 & 67.05 & 0.089 & 109.3 \\
\hline 16 & 0.00 & 0.00 & 0.00 & 70.22 & 0.084 & 110.1 \\
\hline 17 & 0.00 & 1.00 & 1.00 & 63.14 & 0.136 & 109.1 \\
\hline
\end{tabular}

Table 1: Design matrix with compositions of liposomal formulations. 


\section{Stability study}

The physical stability of curcumin-bearing liposomes was assessed by storing the liposomes at two varying temperatures: $25^{\circ} \mathrm{C}$ and $4^{\circ} \mathrm{C}$. The vesicle size and polydispersity index were measured at different time points after diluting with double-distilled water. The experiment was conducted in triplicate.

\section{Preparation of Eudragit S-100 coated calcium alginate beads loaded liposomes}

Liposomes were centrifuged, re-suspended in water, and mixed with alginate solution. The solution was dropped into calcium chloride solution $(100 \mathrm{mmol} / \mathrm{l})$ using a 22 gauge syringe with gradual stirring for $1 \mathrm{hr}$. The unreacted calcium chloride solution was decanted and the beads were washed with deionized water and dried in a vacuum desiccator till they obtained a constant weight.

The beads were coated according to the method reported by Huyghebaert et al. ${ }^{9}$ The coating solution was prepared by dissolving Eudragit-S 100 in $1 \mathrm{M}$ ammonia with the help of stirring for $1 \mathrm{hr}$. Triethyl citrate (a plasticizer) was added to it and further stirred for $1 \mathrm{hr}$. Then alginate beads were dip-coated and air-dried.

\section{Physical characterization of liposomes entrapped eudragit coated alginate beads \\ Determination of the size of beads}

The size of uncoated and coated alginate beads was determined using optical microscopy. The diameters of beads were measured with an eyepiece micrometre on an optical microscope (40X. magnification). Randomly 100 selected beads were measured for each sample.

\section{Drug content}

Approximately $0.5 \mathrm{~g}$ of alginate beads were ground in a pestle. The powder was dissolved in $100 \mathrm{ml}$ of phosphate buffer ( $\mathrm{pH}$ 7.4) containing $0.1 \%$ Triton X-100 by stirring for 6-7 hrs. The solution was filtered through a $0.2 \mu \mathrm{m}$ millipore membrane filter. The concentration of drug was determined by HPLC method as discussed above in section 3.3.3.

\section{In vitro Drug Release Profile}

In vitro drug release from eudragit coated alginate beads bearing curcumin loaded liposomes was assessed according to Souder and Ellenbogen extraction method. ${ }^{10}$ In this study, dissolution/release media used were as follows:

Simulated gastric fluid of $\mathrm{pH}$ 1.2: $1^{\text {st }} \mathrm{hr}$

A mixture of simulated gastric and intestinal fluid of $\mathrm{pH} 4.5: 2$ to $3 \mathrm{hrs}$, Simulated intestinal fluid of $\mathrm{pH}$ 6.8: 4 and $5 \mathrm{hrs}$

Simulated colonic fluid of $\mathrm{pH}$ 7.4: 6 to $8 \mathrm{hrs}$

The in vitro drug release analysis was conducted with the help of a dialysis bag. An accurately weighed amount of enteric-coated beads was kept in a dialysis bag which was placed in a beaker containing $100 \mathrm{~mL}$ simulated fluids at $37 \pm 1^{\circ} \mathrm{C}$. The media was stirred at a constant speed of $100 \mathrm{rpm}$ with magnetic stirring and media were changed as per Souder and Ellenbogen's scheme. Samples from the beaker (one $\mathrm{ml}$ each) were withdrawn and replaced immediately with the same volume of fresh medium at every sampling time. These samples were analyzed for drug content using the HPLC method as discussed above in section 3.3.3.

\section{Swelling studies}

The swelling behavior of coated and uncoated alginate beads was determined in buffer solutions of $\mathrm{pH} 1.2$ and 7.4 at $37 \pm 1{ }^{\circ} \mathrm{C}$. The beads were accurately weighed $\left(\mathrm{W}_{0}\right)$ and immersed in $100 \mathrm{ml}$ of buffer solution. At definite time intervals, the swollen beads were wiped with tissue paper and weighed (Wg). The percentage swelling degree of the beads was computed by the equation:

$$
\% \text { swelling }=\left[\left(\mathrm{Wg}-\mathrm{W}_{0}\right) / \mathrm{W}_{0}\right] \times 100,
$$

Where, $\mathrm{W}_{0}$ is the initial weight of the beads and $\mathrm{Wg}$ is the weight of the alginate beads at equilibrium swelling.

Data analysis All the results are an average of triplicate experiments $(n=3)$ at a given time. The observations were analyzed statistically using one-way analysis of variance ANOVA. The results have been denoted as mean \pm standard deviation (SD).

\section{RESULTS}

The effect of independent variables viz., HSPC: Chol molar ratio $\left(\mathrm{X}_{1}\right)$, curcumin concentration $\left(\mathrm{X}_{2}\right)$, and sonication time $\left(\mathrm{X}_{3}\right)$ were studied on the dependent variables like \%EE of CUR $\left(\mathrm{Y}_{1}\right)$, PDI $\left(\mathrm{Y}_{2}\right)$, and vesicle size $\left(\mathrm{Y}_{3}\right)$ as per Box-Behnken design (BBD). The ten polynomial coefficients $(\beta 1-\beta 10)$ were postulated during mathematical modelling, with $\beta 0$ as intercept (Table 2). All the polynomial coefficients were following the second-order quadratic polynomial model for the analysis of substantial interaction(s) between the explored responses as given in the equation.

The three response variables in the model had a highly significant statistical value $(p>0001)$. The $\mathrm{r}^{2}$ values for all the models were observed in the range 0.9521 and 0.9993 recommending an excellent fit of polynomials equation for responses ( $p<0.0001$ in all the cases). The "lack of fit", ranging between $p=0.7335$ and $p=0.7702$ for all the models were marked to be insignificant confirming the appropriateness of the model. The nearness of magnitude in the adjusted (Adj) and predicted (Pred) $\mathrm{r}^{2}$ (ranging from $0.8906-0.9985$ and $0.7702-0.9966$ ) was also verified as an excellent fit of the data to the produced models. Table 3 depicts the constraints for the predicted solution.

The optimum preparation has a maximum $\% \mathrm{EE}$ of curcumin, minimum $\mathrm{PDI}$, and vesicle size in range $\mathrm{Y}_{1}=(51.250 \leq \mathrm{Y} \leq 72.770), \mathrm{Y}_{2}=(0.070 \leq$ $\mathrm{Y} \leq 0.247)$ and $\mathrm{Y}_{3}=(106.5 . \leq \mathrm{Y} \leq 119.0)$. After optimizing the process and formulation variables, an optimum liposomal formulation was prepared which was then entrapped in the calcium alginate beads. These beads were coated with Eudragit S-100 to make them for colonspecific drug release. The mean diameters of the uncoated and coated

\section{Table 2: Model summary statistics of all responses estimated according} to BBD.

\begin{tabular}{cccc}
\hline Coefficient code & \multicolumn{3}{c}{ Polynomial coefficients for the response variable } \\
\hline & $\%$ EE CUR & PDI & Vesicle size \\
\hline $\mathrm{b}_{0}$ & +70.16 & +0.012 & +110.20 \\
$\mathrm{~b}_{1}$ & +7.26 & -0.015 & +1.39 \\
$\mathrm{~b}_{2}$ & +0.50 & $+0 . .015$ & +0.20 \\
$\mathrm{~b}_{3}$ & -3.55 & +0.063 & -4.26 \\
$\mathrm{~b}_{4}$ & -1.11 & +0.011 & +1.17 \\
$\mathrm{~b}_{5}$ & +0.71 & +0.71 & -0.15 \\
$\mathrm{~b}_{6}$ & -0.79 & -0.010 & -0.63 \\
$\mathrm{~b}_{7}$ & -5.02 & +0.024 & -0.40 \\
$\mathrm{~b}_{8}$ & -0.69 & +0.036 & +1.37 \\
$\mathrm{~b}_{9}$ & -2.42 & +0.054 & +2.30 \\
\hline
\end{tabular}

$\mathrm{Y}=\beta_{1} \mathrm{X}_{1}+\beta_{2} \mathrm{X}_{2}+\beta_{3} \mathrm{X}_{3}+\beta_{4} \mathrm{X}_{1} \mathrm{X}_{2}+\beta_{5} \mathrm{X}_{1} \mathrm{X}_{3}+\beta_{6} \mathrm{X}_{2} \mathrm{X}_{3}+\beta_{7} \mathrm{X}_{1} \mathrm{X}_{2} \mathrm{X}_{3}+\beta_{8} \mathrm{X}_{1} \mathrm{X}_{2}\left(\mathrm{X}_{1}-\mathrm{X}_{2}\right)+$ $\beta_{9} X_{1} X_{3}\left(X_{1}-X_{3}\right)+\beta_{10} X_{2} X_{3}\left(X_{2}-X_{3}\right)$ 
Table 3: Constraint for numeric optimization and predicted solution.

\begin{tabular}{cccc}
\hline \multirow{2}{*}{$\begin{array}{c}\text { Factors (Independent } \\
\text { variables) }\end{array}$} & Goal & \multicolumn{2}{c}{ Levels } \\
\cline { 3 - 4 } & & Low $(-1)$ & High $(+1)$ \\
\hline X1 Molar ratio of HSPC:Chol & In range & $1.5: 0.5$ & $2.5: 1.5$ \\
X2 Curcumin molar & In range & 1 & 5 \\
$\begin{array}{c}\text { concentration (mM) } \\
\text { X3 Sonication time (min) }\end{array}$ & In range & 6 & 8 \\
Response (Dependent variables) & \\
Y1: Entrapment efficiency CUR & Maximum & 51.25 & 72.77 \\
Y\%) & & \\
Y2: PDI & Minimum & 0.080 & 0.247 \\
Y3: Vesicle size (nm) & In range & 106.500 & 119.0 \\
\hline
\end{tabular}

beads were noted to be $1.274 \pm 0.115 \mathrm{~mm}$ and $1.408 \pm 0.156 \mathrm{~mm}$. These liposomes bearing Eudragit coated alginate beads were also characterized for drug release in various simulated gastric fluids which is showing no release upto $6 \mathrm{hrs}$ and $8.5 \%$ release was observed in $6^{\text {th }} \mathrm{hr}$ and after $7 \mathrm{hr}$ fast release $(63.5 \%$ at the end of $48 \mathrm{hrs})$ was noted. The swelling of beads was found to be higher (300\%) at $\mathrm{pH} 7.4$ than that at $\mathrm{pH} 1.2(150 \%)$ at the end of $8 \mathrm{hrs}$.

\section{DISCUSSION}

The current research was intended at preparing and optimizing curcumin-loaded liposomes for colonic delivery. The liposomes were formulated by film casting method and were entrapped in alginate beads and then these were dip-coated with Eudragit S-100.

The optimization was performed by Quality by design approach, Designexpert $^{\oplus}$ software. It was observed that with a rise in the molar ratio of HSPC: Chol there was a gradual rise in EE (\%) of curcumin. It is due to the increase in the amount of lipid and lipid bilayers that imparts an extra space for the drug to entrap, and hence, it has a positive impact on drug entrapment in the given concentration range. Similarly, rising the curcumin concentration led to an increase in the $\mathrm{EE}$ (\%) of curcumin due to the availability of more lipid bilayers for the entrapment of the drug. Nevertheless, an increase in the sonication time led to a decline in the EE (\%) due to the leakage of curcumin from the bilayer. With an increase in the sonication time, there was an initial increase in the EE (\%) followed by a fall in EE on further increase in the sonication time it could be due to the reassembling of lipid molecules to form smaller vesicles having a condensed aqueous compartment, thus leading to drug leaching (Figure $1 \mathrm{~A}$ ). An elevation in the ratio of HSPC:Chol and curcumin concentration caused an increase in the PDI. While a rise in the sonication time led to a significant rise in the PDI due to the breaking of liposomes. (Figure 1B). It was found that with an increase in the molar ratio of HSPC:Chol and curcumin concentration there was an enhancement in the vesicle size of the liposomes. This can be attributed to increasing the lipids bilayers and enhanced rigidity and stability of the vesicles due to the presence of cholesterol molecules. Whereas, increasing the sonication time led to the generation of smaller vesicles due to the high shear stress created by sonication in the liposomal dispersion which may cause disruption of large liposomes to small liposomes ${ }^{11}$ (Figure 1C).

The morphology of drug-loaded liposomes was affirmed by optical microscopy and transmission electron microscopy (TEM) images (Figure 2A and B). The TEM image shows the liposomes in aspherical shape. The average diameter of the liposomes was found to be $109.8 \pm 1.4 \mathrm{~nm}$. Liposomes showed a narrow size distribution with a low
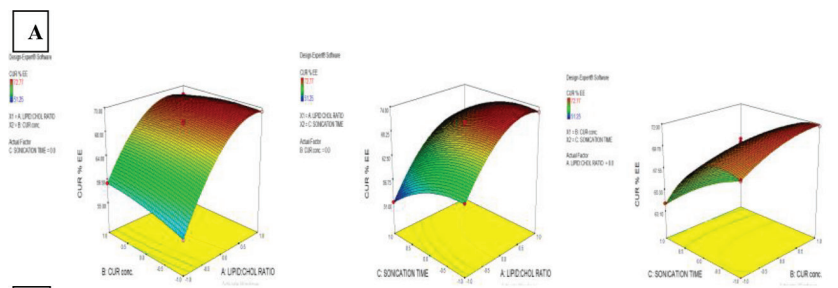

$\mathbf{B}$
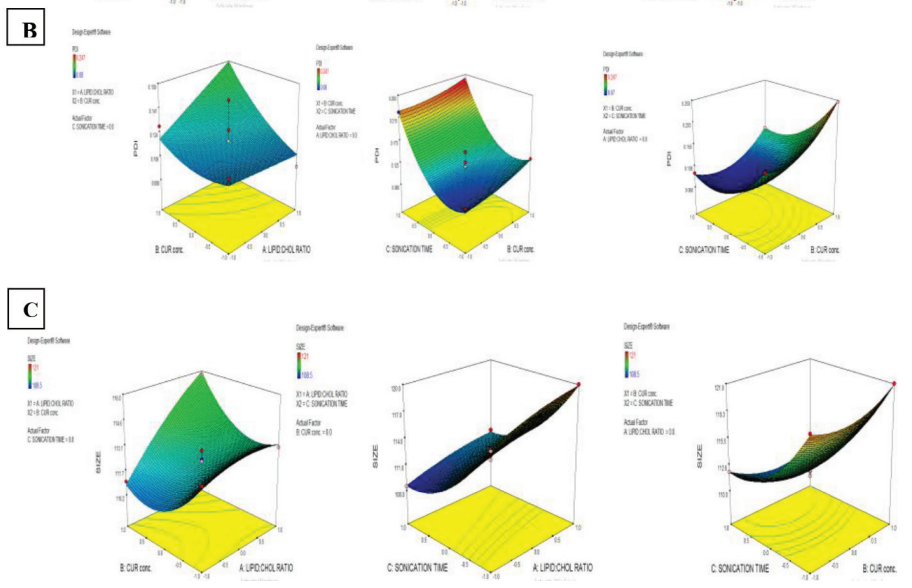

Figure 1: $(A-C)$ shows the 3-D response surfaces for Entrapment efficiency (EE) of CUR, PDI, and vesicle size.
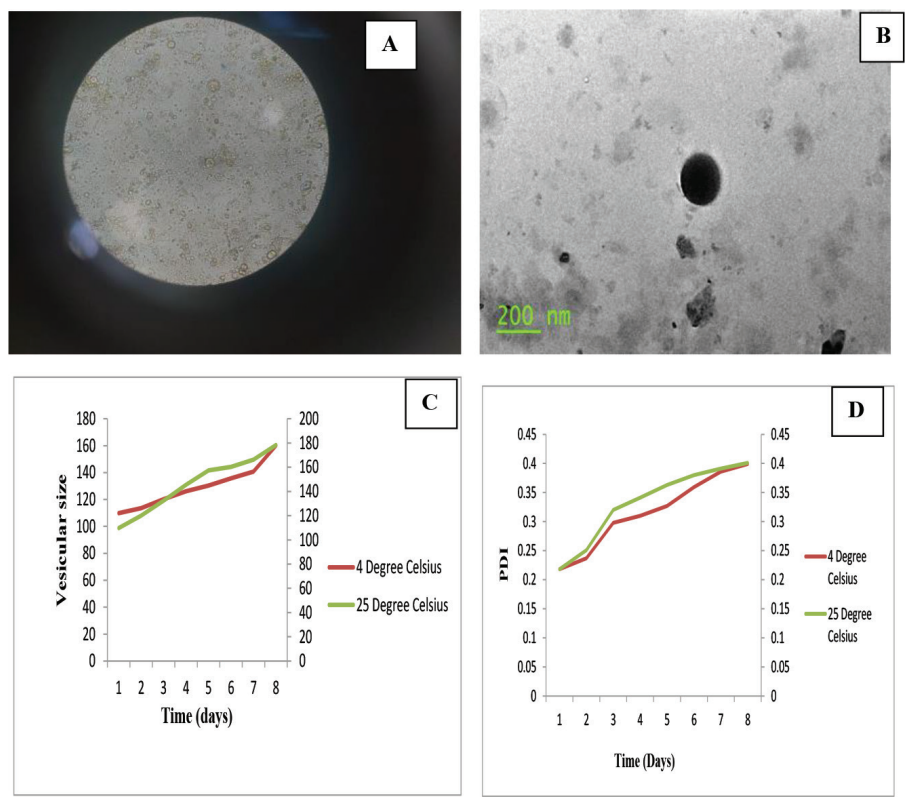

Figure 2: (A) Phase contrast photomicrographs (40x) of liposomes (B) TEM image of liposomes. (C) Effect of storage on vesicle size of liposomes (D) Effect of storage on polydispersity index of liposomes.

polydispersity index i.e. $0.218 \pm 1.2$. The zeta potential of the liposomes was observed to be $+19.30 \pm 2.46 \mathrm{mV}$. The stability study of liposomes exhibited that the liposomes were stable and depicted less tendency to aggregate since there was a minor increase in the size and PDI of the vesicles. The increase in these parameters was comparatively more at $25^{\circ} \mathrm{C}$ than $4^{\circ} \mathrm{C}$ suggesting that the ideal storage condition for liposomes is $4^{\circ} \mathrm{C}$ (Figure $\left.2 \mathrm{C}, \mathrm{D}\right)$.

These liposomes were made colon specific by entrapping them into Eudragit coated alginate beads. The mean diameters of the uncoated and 

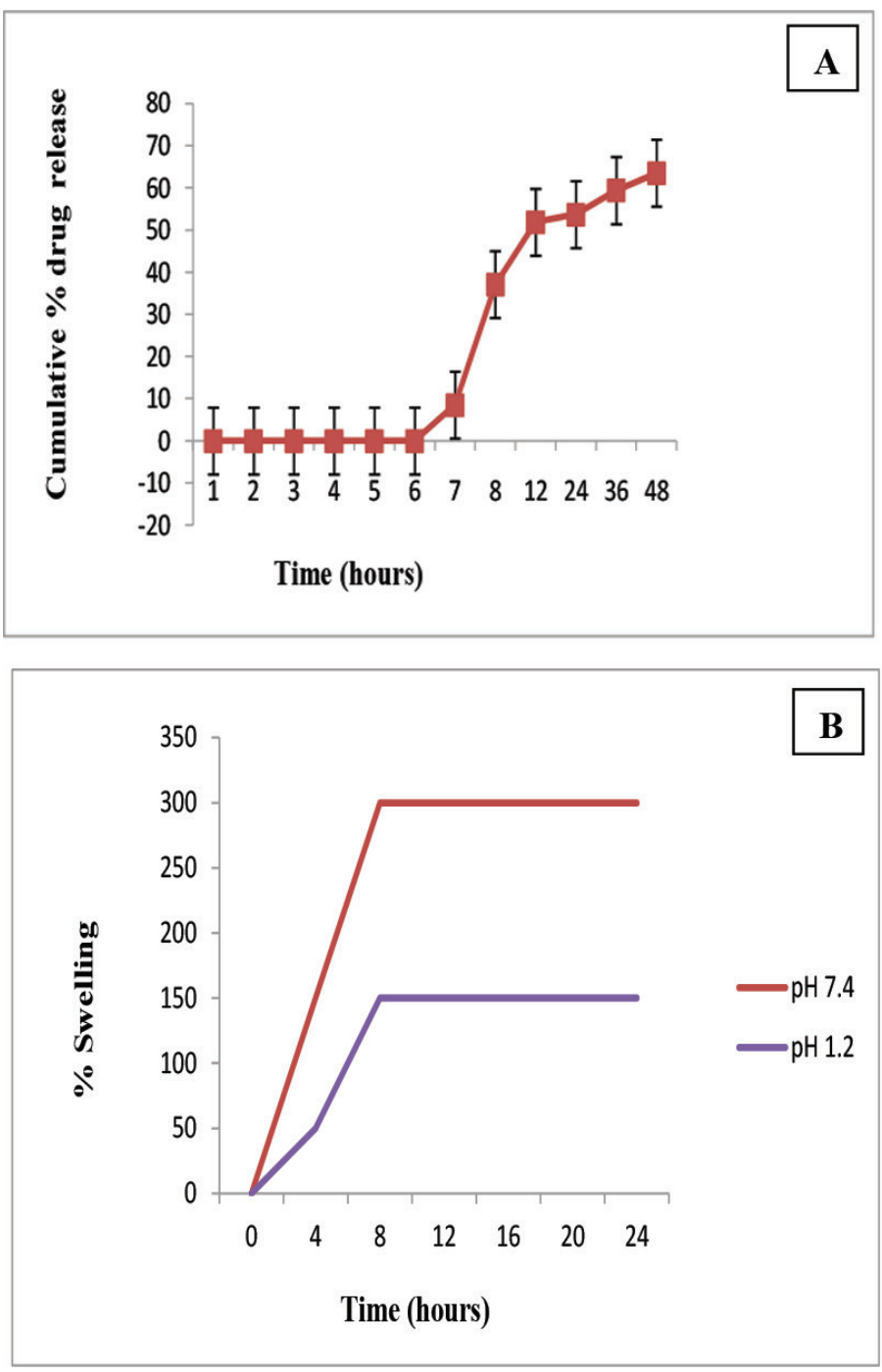

Figure 3: (A) In vitro drug release profile of eudragit S-100 coated beads encapsulating curcumin liposomes in various simulated fluids. Simulated gastric fluid ( $\mathrm{pH} 1.2)$; simulated intestinal fluid ( $\mathrm{pH} 4.5$ and 6.8), simulated colon fluid (pH 7.4). Results are presented as mean $\pm \mathrm{SD}, n=3$.

(B) Determination of $\%$ swelling of beads at $\mathrm{pH} 1.2$ and $\mathrm{pH}$ 7.4.

coated beads were found to be $1.274 \pm 0.115 \mathrm{~mm}$ and $1.408 \pm 0.156 \mathrm{~mm}$, respectively. The increase in the size of the coated beads could be due to the application of eudragit S-100 coating on the beads. ${ }^{12}$ The drug content was in proportion to that of loaded drug ranging from $38 \% \pm 1.2 \%$ to $69 \% \pm 2.3 \% \mathrm{wt} / \mathrm{wt}$. No drug was released up to $6 \mathrm{hr}$, and after the end of 6.5 hrs (i.e. in stimulated intestinal fluid $\mathrm{pH} \mathrm{6.8)} \mathrm{the}$ drug gradually started releasing. The drug was not released from enteric coated beads in the stomach and intestine as they were protected in the upper parts of GIT because of the Eudragit-S-100 coating that dissolves only at $\mathrm{pH}>6.8$. The eudragit coating of the beads disintegrates after entering the colon and polysaccharidase enzyme in the colon causes the degradation of the beads leading to the release of the liposomes. At the end of $48 \mathrm{hrs}, 63.5 \%$ of curcumin was released from the liposomes (Figure 3A). Swelling is an essential characteristic that determines the release behavior of a drug molecule. The swelling property of the beads was determined in buffer solutions with $\mathrm{pH} 1.2$ and 7.4 (Figure $3 \mathrm{~B}$ ). It is noticed that the swelling property of beads is highly affected by the $\mathrm{pH}$ of the medium. The degree of swelling of the beads was found to be higher in $\mathrm{pH} 7.4$ than at $\mathrm{pH}$ 1.2. It could also be due to the ion exchange reaction between $\mathrm{Na}^{+}$ions of the phosphate buffer and $\mathrm{Ca}^{2+}$ ions linked to carboxylic acid groups of alginate. Monovalent ions substitute bivalent ions break the "egg-box" structure and increase in the distance between the polymer chains and enhancing the fluid absorption and swelling of the beads. ${ }^{13}$

\section{CONCLUSION}

In this research, curcumin- loaded liposomes were developed using thin-film hydration method. The various formulation and process variables were optimized using Design of experiment by Design Expert software. The liposomes were spherical in shape, nanometric in size, and depicted a sustained drug release.The developed liposomes were stable at $4^{\circ} \mathrm{C}$ as there was no significant change in the vesicle size and PDI at this temperature. These liposomes were entrapped in the Eudragit S 100 coated alginate beads so as to release curcumin loaded liposomes in the colon. The results propose that the eudragit coated beads entrapped curcumin-loaded liposomes could pave a way for the entrapment of lipophilic drugs like curcumin with high entrapment efficiency and lead to the development of a stable and effective drug delivery system for colon specific drug release.

\section{ACKNOWLEDGEMENT}

The authors are sincerely thankful to Sunpure Extracts Private Limited, Delhi, India, for gifting Curcumin, They are also thankful to DST-FIST and DST PHASE-II PURSE for providing an instrumentation facility.

\section{Funding}

This work was funded by the Indian Council of Medical Research, New Delhi, India (Ref. no. 45/7/2018-Nan/BMS)

\section{CONFLICT OF INTEREST}

The authors declare no conflict of interest.

\section{Author contribution}

Tiwari A: Conducted all the experiments, collected and analyzed the data. Wrote the paper.

Jain SK: Designed and supervised the experiments.

\section{REFERENCES}

1. Malki A, EIRuz RA, Gupta I, Allouch A, Vranic S, Al Moustafa AE. Molecular mechanisms of colon cancer progression and metastasis: recent insights and advancements. Int J Mol Sci. 2020;22(1):130. doi: 10.3390/ijms22010130, PMID 33374459.

2. Kawamori T, Lubet R, Steele VE, Kelloff GJ, Kaskey RB, Rao CV, Reddy BS. Chemopreventive effect of curcumin, a naturally occurring anti-inflammatory agent, during the promotion/progression stages of colon cancer. Cancer Res. 1999;59(3):597-601. PMID 9973206.

3. Johnson JJ, Mukhtar H. Curcumin for chemoprevention of colon cancer. Cancer Lett. 2007;255(2):170-81. doi: 10.1016/j.canlet.2007.03.005, PMID 17448598.

4. Tiwari A, Jain SK. Curcumin based drug delivery systems for cancer therapy. Curr Pharm Des. 2020;26(42):5430-40. doi: 10.2174/138161282666620042909 5503, PMID 32348207.

5. Allen TM. Liposomes. Drugs. 1997;54(4):8-14

6. Bangham AD. Membrane models with phospholipids. Prog Biophys Mol Biol. 1968;18:29-95. doi: 10.1016/0079-6107(68)90019-9, PMID 4894874.

7. Galpin IJ, Kenner GW, Ohlsen SR, Ramage R. Gel filtration of protected peptides on Sephadex G-50 in hexamethylphosphoramide containing 5\% water. J Chromatogr. 1975;106(1):125-9. doi: 10.1016/s0021-9673(01)81054-2, PMID 1150783

8. Fry DW, White JC, Goldman ID. Rapid separation of low molecular weight solutes from liposomes without dilution. Anal Biochem. 1978;90(2):809-15. doi: 10.1016/0003-2697(78)90172-0, PMID 727510

9. Huyghebaert N, Vermeire A, Remon JP. In vitro evaluation of coating polymers for enteric coating and human ileal targeting. Int J Pharm. 2005:298(1):26-37. doi: 10.1016/j.ijpharm.2005.03.032, PMID 15894443. 
10. Souder J, Ellenbogen W. Control of d-amphetamine sulphate sustained release capsule. Drug Stand. 1985;26:77-9.

11. Tefas LR, Sylvester B, Tomuta I, Sesarman A, Licarete E, Banciu M, Porfire A. Development of antiproliferative long-circulating liposomes co-encapsulating doxorubicin and curcumin, through the use of a quality-by-design approach. Drug Des Devel Ther. 2017;11:1605-21. doi: 10.2147/DDDT.S129008, PMID 28579758.
12. Kumari A, Jain A, Hurkat P, Tiwari A, Jain SK. Eudragit S100 coated microsponges for Colon targeting of prednisolone. Drug Dev Ind Pharm. 2018;44(6):902-13 doi: 10.1080/03639045.2017.1420079, PMID 29260916.

13. Segale L, Giovannelli L, Mannina P, Pattarino F. Calcium alginate and calcium alginate-chitosan beads containing celecoxib solubilized in a self-emulsifying phase. Scientifica. 2016;2016:5062706. doi: 10.1155/2016/5062706, PMID 27127680.

Article History: Submission Date : 20-08-2021; Revised Date : 17-09-2021; Acceptance Date : 04-11-2021.

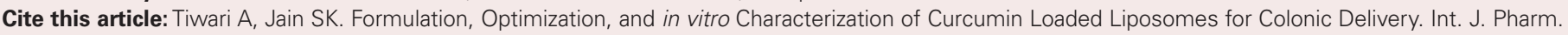
Investigation. 2021;11(4):408-13. 